\title{
CROSS-SECTIONS IN PHOTONUCLEAR REACTIONS WITH MULTIPLE NEUTRON EMISSION
}

\author{
O.A. Bezshyyko², O.M. Vodin ${ }^{1}$, L.O. Golinka-Bezshyyko ${ }^{2}$, A.V. Kotenko ${ }^{2}$, V.A. Kushnir ${ }^{1}$, \\ O.V. Lubynets ${ }^{2}$, V.V. Mitrochenko ${ }^{1}$, S.M. Olejnik ${ }^{1}$, S.A. Perezhogin ${ }^{1}$, C. Vallerand ${ }^{3}$ \\ ${ }^{1}$ National Science Center "Kharkov Institute of Physics and Technology”, Kharkiv, Ukraine; \\ ${ }^{2}$ Taras Shevchenko National University of Kyiv, Kyiv, Ukraine; \\ ${ }^{3}$ Linear Accelerator Laboratory, Orsay, France (LAL) \\ E-mail:vodin@kipt.kharkov.ua
}

The energy dependence of the reaction cross-sections $A(\gamma, x \mathrm{n})(A-x \mathrm{n})$ was studied in the energy range $19 \ldots 70 \mathrm{MeV}$, i.e. beyond Great Dipole Resonance (GDR) region. Experimental data were taken from international database EXFOR for range of nuclear mases $(55<A<209)$. Theoretical values of cross sections were obtained using TALYS-1.8 code. Several models of level densities with both enabled and disabled pre-equilibrium mechanism were considered in our simulations. Obtained results let us to make conclusions about different mechanisms of photonuclear reactions on certain nuclei, energy dependence of their relative contribution.

PACS: $25.20,21.60$

\section{INTRODUCTION}

Nuclear reactions with photons in the input channel have some advantages which are used for investigation of general physical dependencies and some special features of photonuclear reactions. First of all, gamma-quanta do not contribute large angular momentum to the nuclei, and excitation energy of nuclei does not include binding energy of the incident particle. Characteristics of photonuclear reactions are well studied in the energy region of giant dipole resonance and at energies higher than pion production threshold. Energies between GDR and threshold of pion production $(30 \ldots 100 \mathrm{MeV})$ are studied not so well from both experimental and theoretical point of view. It is related with small values of cross sections in this energy region, lack of gamma-quanta sources with fine energy regulation and some historical reasons.

There are two main models of nuclear reactions mechanisms: compound nucleus model and direct reaction model. The main idea of compound nuclei model is that energy of incident particle is uniformly distributed between all the nucleons, and nucleon emission is considered as evaporation process. This model is also called statistical model. There is another mechanism considering particle emission before statistical equilibrium is established. The nucleon can be knocked out with the incident particle; this process is called direct reaction. It is clear that increasing of number of interactions in the nucleus (increasing of reaction time) leads to reduction of the connection between input and output channels and increasing the contribution of statistical processes.

There are several program codes for nuclear reactions description. One of them is TALYS [1], which has an open source. It can be used for evaluation of cross sections, isomeric ratios and other characteristics of nuclear reactions with neutrons, protons, photons, deuterons, ${ }^{3} \mathrm{H},{ }^{3} \mathrm{He}$ and $\alpha$-particles in the input channel.

In the TALYS code modern model approaches for description of direct reactions, pre-equilibrium processes, reactions with compound nuclei production and fission processes are implemented. Reaction mechanisms are considered in wide ranges of incident particle energies $\left(10^{11} \mathrm{MeV}<E<1000 \mathrm{GeV}\right)$ and target nuclei masses $(5<A<339)$. An important advantage of
TALYS code is automatic use of model parameters and estimated nuclear data from RIPL-3 [2] library.

TALYS provides 6 model approaches (LD1-LD6) for level density evaluation: 3 phenomenological models and 3 level density sets derived from microscopic models.

LD1: Constant temperature + Fermi gas model. In this model introduced by Gilbert and Cameron [3], the excitation energy range is divided into a low energy part from $0 \mathrm{MeV}$ up to a matching energy $E_{\mathrm{M}}$, where the socalled constant temperature law applies and a high energy part above, where the Fermi gas model applies. Hence, for the total level density we have

$$
\begin{array}{ll}
\rho^{t o t}\left(E_{x}\right)=\rho_{F}^{t o t}\left(E_{x}\right) & \text { if } E_{x}>E_{M}, \\
\rho^{t o t}\left(E_{x}\right)=\rho_{T}^{t o t}\left(E_{x}\right) & \text { if } E_{x}<E_{M} .
\end{array}
$$

LD2: Back-shifted Fermi gas model. In the Backshifted-Fermi gas Model (BFM) [4], the pairing energy is treated as an adjustable parameter and the Fermi gas expression is used all the way down to $E_{0}$.

LD3: Generalized superfluid model (GSM). Model takes superconductive pairing correlations into account according to the Bardeen-Cooper-Schrieffer theory. The phenomenological version of the model $[5,6]$ is characterized by a phase transition from a superfluid behavior at low energy, where pairing correlations strongly influence the level density, to a high energy region which is described by the Fermi gas model. The GSM thus resembles the constant temperature model to the extent that it distinguishes between a low energy and a high energy region, although for the GSM this distinction follows naturally from the theory and does not depend on specific discrete levels that determine a matching energy. Instead, the model automatically provides a constant temperature-like behavior at low energies.

LD4: Microscopic level densities (Skyrme force) from Goriely's tables. Using this model allows to read tables of microscopic level densities from RIPL database. These table were computed by $S$. Goriely on the basis of Hartree-Fock calculations for excitation energies up to $150 \mathrm{MeV}$ and for spin values up to $I=30$.

LD5: Microscopic level densities (Skyrme force) from Hilaire's combinatorial tables. The combinatorial model includes a detailed microscopic calculation of the 
intrinsic state density and collective enhancement. The only phenomenological aspect of the model is a simple damping function for the transition from spherical to deformed.

LD6: Microscopic level densities (temperature dependent HFB, Gogny force) from Hilaire's combinatorial tables.

We consider reactions both with enabled and disabled pre-equilibrium mechanism. Pre-equilibrium mechanism of nuclear reactions is an intermediate type between direct reaction and reaction via compound nuclei. Pre-equilibrium emission takes place after the first stage of the reaction but long before statistical equilibrium of the compound nucleus is attained. The preequilibrium contribution becomes only sizable for incident energies several $\mathrm{MeV}$ higher than the excitation energy of the last discrete level of the target nucleus.

\section{METHOD}

There are two methods of cross section evaluation. The first way is direct measurement of cross section for a certain value of incident particle energy. The spectra of incident gamma-quanta are assumed to be monoenergetic.

If the incident particles spectrum is substantially different from monoenergetic (especially in experiments with bremsstrahlung $\gamma$-quants) the bremsstrahlung spectrum averaged cross section is calculated.

The reaction yield is determined as

$$
Y\left(E_{\max }\right)=N_{t} \int_{E_{t h}}^{E_{\max }} \sigma(E) W\left(E_{\gamma}, E_{\max }\right) d E,
$$

where $N_{t}$ is the number of target nuclei; $E_{\max }-$ maximum energy of incident particles; $\sigma(E)$ - photonuclear reaction cross section; $W\left(E_{\gamma}, E_{\max }\right)$ - energy spectrum of incident particles; $E_{t h}$ - threshold energy of photonuclear reaction.

Energy spectrum depends on $\gamma$-quantum production cross section. It is clear, because $W\left(E_{\gamma}, E_{\max }\right)$ is energy distribution of particles:

$$
W\left(E_{\gamma}, E_{\max }\right)=\frac{d N}{d E},
$$

where $N$ is the number of $\gamma$-quanta emitted from bremsstrahlung target. The number of $\gamma$-quanta emitted from bremsstrahlung target into solid angle $d \Omega$ is

$$
d N=N_{0} \frac{n}{S} \frac{d \sigma}{d \Omega} d \Omega,
$$

where $N_{0}$ is the number of electrons interacting with bremsstrahlung target; $n$ - number of bremsstrahlung target nuclei with cross-section of the target $S$.

The expression for the flux of $\gamma$-quanta with energies in the range $\left(E_{\gamma} \ldots E_{\gamma}+d E_{\gamma}\right)$ emitted into the solid angle $d \Omega$ can be written in the following form:

$$
d W\left(E_{\gamma}, E_{\max }\right)=N_{0} \frac{n}{S} \frac{d^{2} \sigma}{d \Omega d E_{\gamma}} d \Omega .
$$

Integrating (4) over the solid angle we have

$$
W\left(E_{\gamma}, E_{\max }\right)=\int_{\Omega} N_{0} \frac{n}{S} \frac{d^{2} \sigma}{d \Omega d E_{\gamma}} d \Omega \text {. }
$$

Assuming the target to be thin (twice thinner than radiation length of material [7]), we use the bremsstrahlung energy spectrum calculated in the work [8]. The cross section of bremsstrahlung $\gamma$-quanta production is called Shiff spectrum [9]

$$
\frac{d \sigma}{d \Omega}=\frac{1}{2 \pi} \frac{4 Z}{137} r_{0}^{2}\left(\frac{E_{0}}{m c^{2}}\right) \frac{d E_{\gamma}}{E_{\gamma}}\left[\frac{E_{0}^{2}+E^{2}}{E_{0}^{2}} \ln M(0)-\frac{\left(E_{0}+E\right)^{2}}{E_{0}^{2}}\right],
$$

where $E_{0}$ is the total energy of the electron before its interaction with the target; $E$ is the total energy of the scattered electron; $Z$ - atom number of target material; $r_{0}$ - classical electron radius;

$$
\frac{1}{M(0)}=\left(\frac{m c^{2} E_{\gamma}}{2 E_{0} E}\right)^{2}+\frac{Z^{2 / 3}}{111^{2}} \text {. }
$$

In Shiff's approximation $d^{2} \sigma / d \Omega d E_{\gamma}$ is assumed not to have angle dependence, and $\gamma$-qaunta emission is limited with solid angle $\Omega_{0}$. Then energy spectrum $W\left(E_{\gamma}, E_{\max }\right)$ is proportional to $d^{2} \sigma / d \Omega d E_{\gamma}$ with proportional coefficient $N_{0}(\mathrm{n} / \mathrm{s}) \Omega_{0}$.

The bremsstrahlung spectrum averaged cross-section by definition is:

$$
\left\langle\sigma\left(E_{\max }\right)\right\rangle=\frac{Y\left(E_{\max }\right)}{\int_{E_{t h}}^{E_{\max }} W\left(E_{\gamma}, E_{\max }\right) d E} .
$$

Considering (1) - (7) we obtain the expression for bremsstrahlung spectrum averaged cross section:

$$
\left\langle\sigma\left(E_{\max }\right)\right\rangle=\frac{\int_{E_{t h}}^{E_{\max }} \sigma\left(E_{\gamma}\right) \frac{d^{2} \sigma}{d \Omega \mathrm{d} E_{\gamma}} d E_{\gamma}}{\int_{E_{t h}}^{E_{\max }} \frac{d^{2} \sigma}{d \Omega \mathrm{d} E_{\gamma}} d E_{\gamma}} .
$$

\section{ANALYSIS}

We observe a good agreement between experimental and theoretically predicted values of cross-sections of photonuclear reactions $(\gamma, 3 \mathrm{n})$ for a large set of target nuclei: ${ }^{55} \mathrm{Mn},{ }^{59} \mathrm{Co},{ }^{94} \mathrm{Zr},{ }^{96} \mathrm{Mo},{ }^{121} \mathrm{Sn},{ }^{127} \mathrm{I},{ }^{133} \mathrm{Cs},{ }^{138} \mathrm{Ba}$, ${ }^{139} \mathrm{La}{ }^{141} \mathrm{Pr},{ }^{159} \mathrm{~Tb},{ }^{165} \mathrm{Ho},{ }^{175} \mathrm{Lu},{ }^{181} \mathrm{Ta},{ }^{186} \mathrm{~W},{ }^{190} \mathrm{Os},{ }^{197} \mathrm{Au}$, ${ }^{209} \mathrm{~Pb},{ }^{209} \mathrm{Bi}$. Fig. 1 illustrates a good agreement between experimental data and theories.

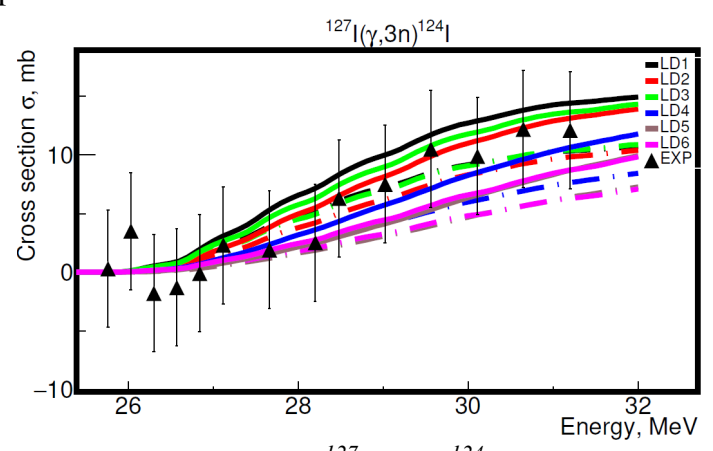

Fig. 1. ${ }^{127} I(\gamma, 3 n)^{124} I$

Also there are reactions with not so good agreement between experimental data and theory: ${ }^{153} \mathrm{Eu}(\gamma, 3 \mathrm{n}){ }^{150} \mathrm{Eu}$, ${ }^{160} \mathrm{Gd}(\gamma, 3 \mathrm{n}){ }^{157} \mathrm{Gd}, \quad{ }^{189} \mathrm{Os}(\gamma, 3 \mathrm{n}){ }^{186} \mathrm{Os}, \quad{ }^{192} \mathrm{Os}(\gamma, 3 \mathrm{n}){ }^{189} \mathrm{Os}$. Fig. 2 illustrates differences between experimental data and theory.

In order to simplify comparison of bremsstrahlung spectrum averaged cross sections measured by different research groups with cross section values predicted by 6 theoretical models, both these values for photonuclear reactions with bremsstrahlung incident $\gamma$-quanta are represented in Table. 


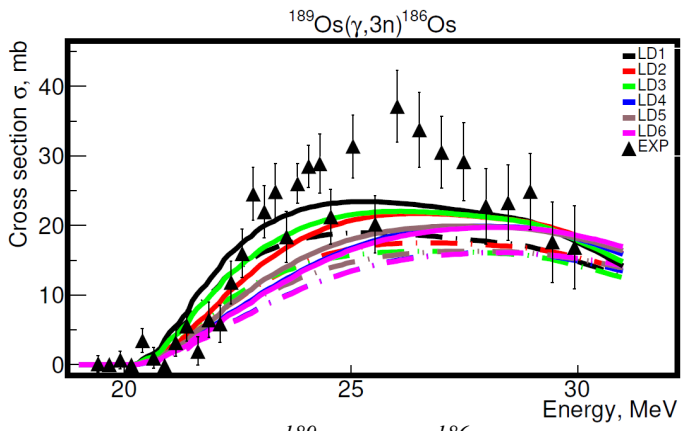

Fig. 2. ${ }^{189} \mathrm{Os}(\gamma, 3 n)^{186} \mathrm{Os}$
In the first column of Table there is a photonuclear reaction and its threshold $\left(E_{t h}\right)$. In the second column there is maximum energy of bremsstrahlung photons. In the third column there is an experimental value of bremsstrahlung spectrum averaged cross-section $\sigma\left(E_{\max }\right)$. The fourth column contains reference to the experimental data represented in the third column; in the 5-th and 6-th column there are theoretically predicted values of bremsstrahlung spectrum averaged cross sections calculated according to (8). These values are separated with slashes (from 1-st (LD1) to 6-th (LD6) level density model, both with enabled and disabled preequilibrium mechanism).

Comparison of bremsstrahlung spectrum averaged cross sections of different authors

\begin{tabular}{|c|c|c|c|c|c|}
\hline \multirow{2}{*}{ Reaction } & \multirow{2}{*}{$E_{\text {max }}, \mathrm{MeV}$} & \multirow{2}{*}{$<\sigma>, \mathrm{mb}$} & \multirow{2}{*}{ Ref. } & \multicolumn{2}{|c|}{ Theoretical value of $\langle\sigma\rangle$, mb } \\
\hline & & & & disabled pre-equilibrium & enabled pre-equilibrium \\
\hline${ }^{89} \mathrm{Y}(\gamma, 3 \mathrm{n}){ }^{86} \mathrm{Y}$ & 45 & $1.48 \pm 0.21$ & {$[10]$} & $2.96 / 2.35 / 2.47 / 0.82 / 1.31 / 0.47$ & $1.87 / 1.56 / 1.63 / 0.68 / 0.89 / 0.40$ \\
\hline$E_{t h}=32.6 \mathrm{MeV}$ & 55 & $1.99 \pm 0.30$ & & $2.96 / 2.46 / 2.59 / 0.79 / 1.45 / 0.60$ & 2.06/1.77/1.82/0.88/1.09/0.63 \\
\hline $\begin{array}{l}{ }^{99} \mathrm{Tc}(\gamma, 3 \mathrm{n}){ }^{96} \mathrm{Tc} \\
E_{t h}=25.7 \mathrm{MeV}\end{array}$ & 36 & $2.30 \pm 0.17$ & {$[11]$} & $8.13 / 6.99 / 5.54 / 6.08 / 5.20 / 3.93$ & $5.46 / 4.94 / 4.10 / 4.08 / 3.62 / 2.72$ \\
\hline${ }^{197} \mathrm{Au}(\gamma, 3 \mathrm{n}){ }^{194} \mathrm{Au}$ & 50 & $8.7 \pm 0.6$ & {$[12]$} & $4.15 / 3.79 / 3.37 / 3.21 / 5.03 / 5.01$ & 7.16/6.50/6.33/4.32/6.08/6.30 \\
\hline$E_{t h}=23.0 \mathrm{MeV}$ & 60 & $7.7 \pm 0.4$ & & $4.18 / 3.79 / 3.54 / 2.92 / 4.42 / 4.44$ & $6.34 / 5.73 / 5.56 / 3.85 / 5.43 / 5.59$ \\
\hline & 70 & $6.8 \pm 0.4$ & & $3.72 / 3.37 / 3.15 / 2.60 / 3.93 / 3.95$ & $5.80 / 5.24 / 5.07 / 3.54 / 4.99 / 5.13$ \\
\hline${ }^{209} \mathrm{Bi}(\gamma, 3 \mathrm{n}){ }^{206} \mathrm{Bi}$ & 50 & $0.652 \pm 0.040$ & {$[13]$} & $3.38 / 3.50 / 3.18 / 4.42 / 4.49 / 5.03$ & 7.49/7.34/7.87/7.21/6.84/6.38 \\
\hline$E_{t h}=22.4 \mathrm{MeV}$ & 55 & $0.673 \pm 0.065$ & & $4.04 / 4.06 / 3.99 / 4.56 / 4.59 / 4.80$ & $7.00 / 6.85 / 7.33 / 6.76 / 6.43 / 6.01$ \\
\hline & 60 & $0.701 \pm 0.048$ & & $3.92 / 3.92 / 3.91 / 4.32 / 4.34 / 4.48$ & $6.62 / 6.47 / 6.91 / 6.40 / 6.10 / 5.71$ \\
\hline & 65 & $0.783 \pm 0.077$ & & $3.70 / 3.70 / 3.69 / 4.06 / 4.09 / 4.21$ & $6.31 / 6.17 / 6.57 / 6.11 / 5.84 / 5.47$ \\
\hline & 70 & $0.819 \pm 0.088$ & & $3.50 / 3.50 / 3.49 / 3.84 / 3.87 / 3.99$ & $6.05 / 5.92 / 6.30 / 5.88 / 5.62 / 5.27$ \\
\hline $\begin{array}{c}{ }^{89} \mathrm{Y}(\gamma, 4 \mathrm{n}){ }^{85} \mathrm{Y} \\
E_{t h}=42.1 \mathrm{MeV}\end{array}$ & 55 & $0.93 \pm 0.160$ & {$[10]$} & $1.62 / 1.23 / 1.24 / 0.169 / 0.30 / 0.12$ & $0.79 / 0.64 / 0.64 / 0.13 / 0.16 / 0.088$ \\
\hline${ }^{197} \mathrm{Au}(\gamma, 4 \mathrm{n}){ }^{193} \mathrm{Au}$ & 50 & $7.3 \pm 0.3$ & {$[12]$} & $6.15 / 6.96 / 6.80 / 6.82 / 6.30 / 5.47$ & $4.91 / 5.21 / 5.55 / 4.94 / 4.47 / 4.12$ \\
\hline$E_{t h}=30.0 \mathrm{MeV}$ & 60 & $6.0 \pm 0.3$ & & $5.36 / 5.89 / 5.84 / 6.06 / 5.90 / 4.68$ & $4.52 / 4.81 / 5.02 / 4.80 / 4.58 / 4.02$ \\
\hline & 70 & $5.2 \pm 0.3$ & & $4.61 / 5.06 / 5.02 / 5.22 / 5.10 / 4.03$ & $4.13 / 4.38 / 4.54 / 4.43 / 4.2 / 3.75$ \\
\hline${ }^{208} \mathrm{~Pb}(\gamma, 4 \mathrm{n}){ }^{204} \mathrm{~Pb}$ & 50 & $0.285 \pm 0.045$ & [13] & $4.68 / 6.39 / 0.00 / 6.27 / 5.73 / 5.53$ & $4.92 / 4.80 / 0.0624 / 4.66 / 4.17 / 4.04$ \\
\hline$E_{t h}=28.9 \mathrm{MeV}$ & 60 & $0.344 \pm 0.025$ & & $4.52 / 5.33 / 0.00 / 5.32 / 5.508 / 5.13$ & $4.50 / 4.46 / 0.105 / 4.42 / 4.39 / 4.17$ \\
\hline & 70 & $0.373 \pm 0.016$ & & $3.90 / 4.59 / 0.00 / 4.58 / 4.94 / 4.44$ & $4.12 / 4.09 / 0.135 / 4.08 / 4.21 / 3.90$ \\
\hline${ }^{209} \mathrm{Bi}(\gamma, 4 \mathrm{n}){ }^{205} \mathrm{Bi}$ & 50 & $0.315 \pm 0.054$ & [13] & $4.43 / 5.19 / 5.25 / 5.36 / 3.07 / 3.46$ & $4.62 / 4.64 / 5.01 / 4.15 / 2.86 / 2.51$ \\
\hline$E_{t h}=29.4 \mathrm{MeV}$ & 55 & $0.374 \pm 0.035$ & & $4.65 / 5.09 / 5.13 / 5.18 / 3.26 / 3.36$ & $4.40 / 4.46 / 4.73 / 4.09 / 2.92 / 2.59$ \\
\hline & 60 & $0.389 \pm 0.051$ & & $4.34 / 4.69 / 4.72 / 4.76 / 3.08 / 3.10$ & $4.17 / 4.23 / 4.46 / 3.92 / 2.86 / 2.54$ \\
\hline & 65 & $0.403 \pm 0.056$ & & $4.01 / 4.33 / 4.36 / 4.39 / 2.85 / 2.86$ & $3.97 / 4.03 / 4.23 / 3.76 / 2.77 / 2.47$ \\
\hline & 70 & $0.420 \pm 0.055$ & & $3.74 / 4.04 / 4.06 / 4.10 / 2.66 / 2.67$ & $3.81 / 3.86 / 4.04 / 3.62 / 2.70 / 2.40$ \\
\hline${ }^{197} \mathrm{Au}(\gamma, 5 \mathrm{n}){ }^{192} \mathrm{Au}$ & 50 & $3.4 \pm 0.3$ & [12] & $2.43 / 2.17 / 2.42 / 1.57 / 0.92 / 0.50$ & $1.45 / 1.35 / 1.54 / 0.93 / 0.54 / 0.33$ \\
\hline$E_{t h}=38.7 \mathrm{MeV}$ & 60 & $4.5 \pm 0.4$ & & $3.95 / 3.77 / 3.91 / 3.33 / 2.90 / 0.90$ & $2.55 / 2.49 / 2.62 / 2.08 / 1.76 / 0.80$ \\
\hline & 70 & $4.0 \pm 0.3$ & & $3.40 / 3.27 / 3.36 / 3.03 / 2.81 / 0.79$ & $2.43 / 2.39 / 2.46 / 2.10 / 1.88 / 0.93$ \\
\hline${ }^{208} \mathrm{~Pb}(\gamma, 5 \mathrm{n}){ }^{203} \mathrm{~Pb}$ & 50 & $0.055 \pm 0.010$ & [13] & $3.32 / 2.89 / 0.00 / 2.36 / 1.24 / 0.93$ & $2.01 / 1.74 / 0.00 / 1.41 / 0.74 / 0.55$ \\
\hline$E_{t h}=38.7 \mathrm{MeV}$ & 60 & $0.145 \pm 0.025$ & & $4.54 / 4.55 / 0.00 / 4.38 / 3.39 / 2.66$ & $3.06 / 3.01 / 0.01 / 2.83 / 2.11 / 1.69$ \\
\hline & 70 & $0.187 \pm 0.024$ & & $3.85 / 3.96 / 0.00 / 3.90 / 3.72 / 2.55$ & $2.91 / 2.94 / 0.02 / 2.84 / 2.53 / 1.85$ \\
\hline${ }^{209} \mathrm{Bi}(\gamma, 5 \mathrm{n}){ }^{204} \mathrm{Bi}$ & 50 & $0.058 \pm 0.006$ & {$[13]$} & $5.06 / 4.13 / 4.97 / 3.14 / 0.99 / 0.86$ & $2.96 / 2.50 / 3.10 / 1.81 / 0.59 / 0.50$ \\
\hline$E_{t h}=37.9 \mathrm{MeV}$ & 55 & $0.101 \pm 0.022$ & & $6.27 / 5.53 / 6.03 / 4.92 / 1.69 / 1.53$ & $3.79 / 3.42 / 3.84 / 2.89 / 1.06 / 0.92$ \\
\hline & 60 & $0.149 \pm 0.015$ & & $5.91 / 5.38 / 5.61 / 5.15 / 1.81 / 1.72$ & $3.78 / 3.50 / 3.74 / 3.17 / 1.24 / 1.10$ \\
\hline
\end{tabular}




\begin{tabular}{|c|c|c|c|c|c|}
\hline \multirow{2}{*}{ Reaction } & \multirow{2}{*}{$E_{\max }, \mathrm{MeV}$} & \multirow{2}{*}{$<\sigma>, \mathrm{mb}$} & \multirow{2}{*}{ Ref. } & \multicolumn{2}{|c|}{ Theoretical value of $\langle\sigma\rangle$, mb } \\
\hline & & & & disabled pre-equilibrium & enabled pre-equilibrium \\
\hline & 65 & $0.163 \pm 0.023$ & & $5.26 / 4.84 / 4.98 / 4.73 / 1.66 / 1.63$ & $3.57 / 3.33 / 3.49 / 3.09 / 1.27 / 1.14$ \\
\hline & 70 & $0.171 \pm 0.019$ & & $4.72 / 4.35 / 4.46 / 4.27 / 1.50 / 1.48$ & $3.36 / 3.14 / 3.26 / 2.94 / 1.26 / 1.12$ \\
\hline${ }^{197} \mathrm{Au}(\gamma, 6 \mathrm{n}){ }^{191} \mathrm{Au}$ & 60 & $2.8 \pm 0.5$ & [12] & $2.00 / 1.90 / 2.07 / 1.49 / 1.12 / 0.15$ & $1.06 / 1.04 / 1.16 / 0.78 / 0.586 / 0.13$ \\
\hline$E_{t h}=45.7 \mathrm{MeV}$ & 70 & $3.6 \pm 0.5$ & & $3.00 / 3.03 / 3.18 / 2.86 / 2.54 / 0.24$ & $1.70 / 1.76 / 1.86 / 1.56 / 1.37 / 0.33$ \\
\hline $\begin{array}{c}{ }^{208} \mathrm{~Pb}(\gamma, 6 \mathrm{n}){ }^{202} \mathrm{~Pb} \\
E_{\text {th }}=44.2 \mathrm{MeV}\end{array}$ & 70 & $0.106 \pm 0.023$ & [13] & $4.60 / 4.45 / 0.00 / 4.30 / 2.82 / 1.61$ & $2.77 / 2.60 / 0.00 / 2.44 / 1.54 / 0.93$ \\
\hline${ }^{209} \mathrm{Bi}(\gamma, 6 \mathrm{n}){ }^{203} \mathrm{Bi}$ & 60 & $0.023 \pm 0.004$ & [13] & $4.19 / 3.47 / 4.51 / 2.71 / 0.41 / 0.43$ & $2.14 / 1.85 / 2.46 / 1.36 / 0.23 / 0.22$ \\
\hline$E_{t h}=45.1 \mathrm{MeV}$ & 65 & $0.057 \pm 0.008$ & & $4.94 / 4.20 / 5.21 / 3.95 / 0.53 / 0.67$ & $2.61 / 2.31 / 2.92 / 2.02 / 0.33 / 0.36$ \\
\hline & 70 & $0.105 \pm 0.022$ & & $4.69 / 4.02 / 4.91 / 4.13 / 0.52 / 0.72$ & $2.61 / 2.32 / 2.87 / 2.21 / 0.38 / 0.42$ \\
\hline
\end{tabular}

On Figs. 3-16 there are presented theoretical values of cross sections (solid line corresponds to disabled preequilibrium mechanism, dotted line - to enabled) and experimental data (black triangles). We can see that close to the threshold, theoretical values of crosssections calculated with and without taking into account pre-equilibrium processes are very close that means that near the threshold statistical processes dominate. Generally, at energies far from the threshold, enabled preequilibrium mechanism gives results which better agree with experimental data.

For some reactions we observe a good agreement between theoretical and experimental data:

$\rightarrow{ }^{89} \mathrm{Y}(\gamma, 3 n){ }^{86} \mathrm{Y}$ is well-described with LD2 and LD3 with pre-equilibrium mechanism;

$\rightarrow{ }^{89} \mathrm{Y}(\gamma, 4 \mathrm{n}){ }^{85} \mathrm{Y}$ is well described with 1-st level density model with enabled pre-equilibrium mechanism;

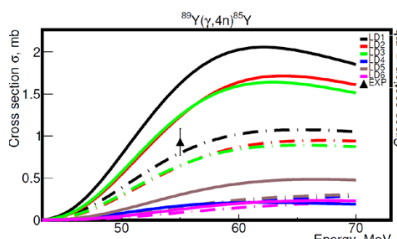

Fig. 3. ${ }^{89} Y(\gamma, 4 n)^{85} Y$. EXP [10]

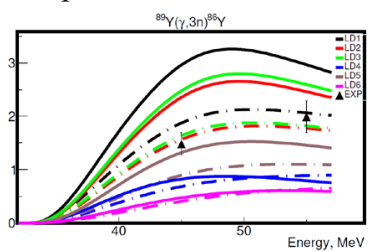

Fig. $4 .{ }^{89} Y(\gamma, 3 n)^{86} Y$. EXP [10] $\rightarrow{ }^{197} \mathrm{Au}(\gamma, 4 \mathrm{n}){ }^{193} \mathrm{Au}$ is well-described with LD1 with disabled pre-equilibrium mechanism;

There are reactions which demonsrate decent agreement between theoretical predictions and experimental values.

$\rightarrow{ }^{99} \mathrm{Tc}(\gamma, 3 \mathrm{n})^{96} \mathrm{Tc}$ can be described with LD6 with enabled pre-equilibrium mechanism;

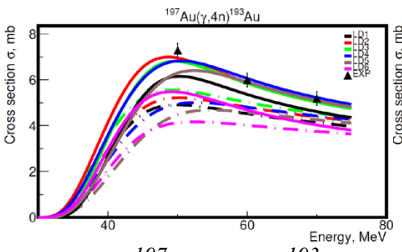

Fig. 5. ${ }^{197} \mathrm{Au}(\gamma, 4 n)^{193} \mathrm{Au}$. EXP [12]

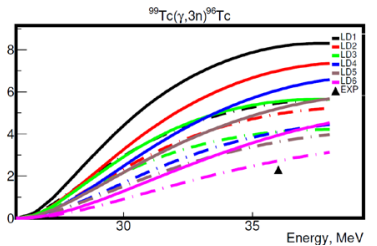

Fig. $6 .{ }^{99} T c(\gamma, 3 n)^{96} T c$. EXP [11] $\rightarrow{ }^{197} \mathrm{Au}(\gamma, 6 \mathrm{n}){ }^{191} \mathrm{Au}$ can be described with LD3 without pre-equilibrium mechanism;

$\rightarrow$ for ${ }^{197} \mathrm{Au}(\gamma, 5 \mathrm{n}){ }^{192} \mathrm{Au}$ the shape of LD1, LD2, LD3 models repeats the shape of experimental data well, the difference between these theoretical models and experimental data is of one order with standard error;

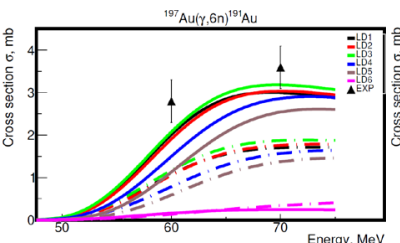

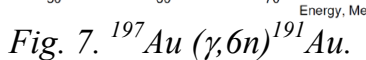

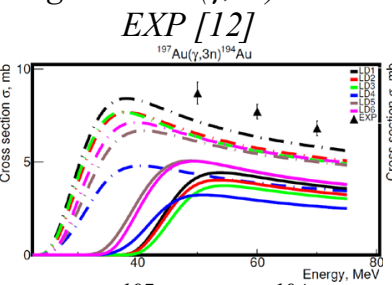

Fig. 9. ${ }^{197} \mathrm{Au}(\gamma, 3 n)^{194} \mathrm{Au}$.

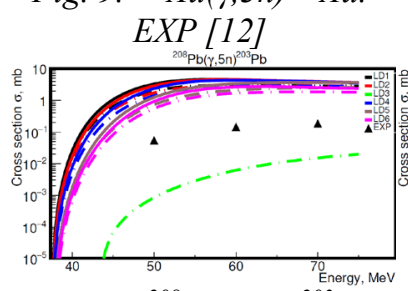

Fig. 11. ${ }^{208} \mathrm{~Pb}(\gamma, 5 n)^{203} \mathrm{~Pb}$. EXP [13]

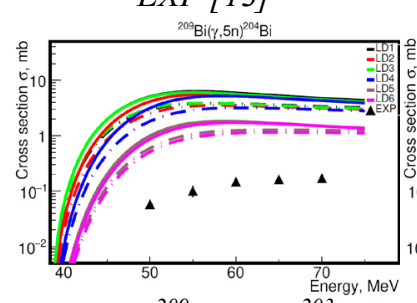

Fig. 13. ${ }^{209} \mathrm{Bi}(\gamma, 6 n)^{200} \mathrm{Bi}$. EXP [13]

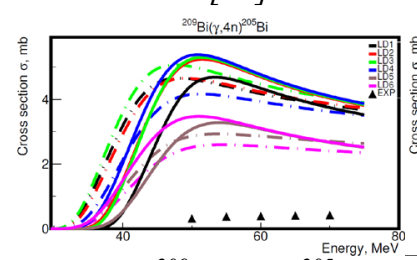

Fig. 15. ${ }^{209} \mathrm{Bi}(\gamma, 4 n)^{205} \mathrm{Bi}$. EXP [13]

For the rest of reactions we observe a large disagreement between theoretical models among themselves; and experimental data do not agree with any of them.

$\rightarrow$ For ${ }^{197} \mathrm{Au}(\gamma, 3 \mathrm{n}){ }^{194} \mathrm{Au}$ we observe a significant difference between models with enabled and disabled preequilibrium mechanism;

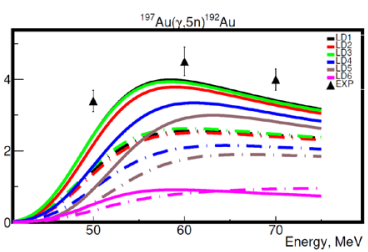

Fig. $8 .{ }^{197} \mathrm{Au}(\gamma, 5 n)^{192} \mathrm{Au}$.

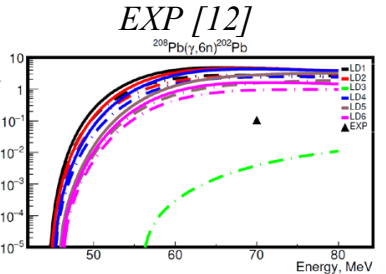

Fig. $10 .{ }^{208} \mathrm{~Pb}(\gamma, 6 n)^{202} \mathrm{~Pb}$.
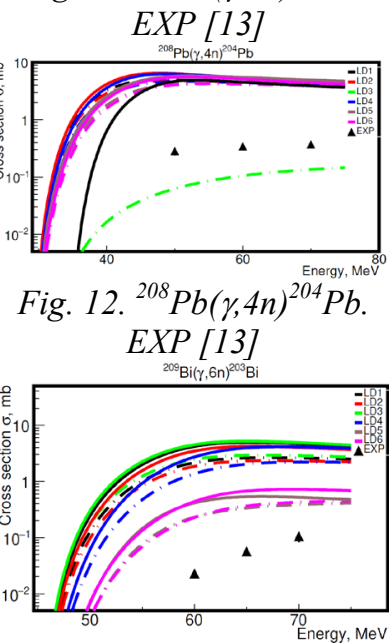

Fig. 14. ${ }^{209} \mathrm{Bi}(\gamma, 5 n)^{204} \mathrm{Bi}$. EXP [13]

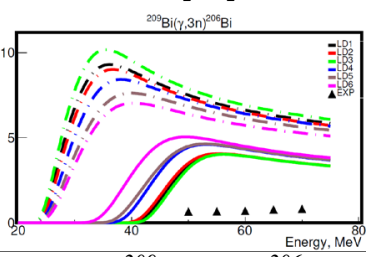

Fig. $16 .{ }^{209} \mathrm{Bi}(\gamma, 3 \mathrm{n})^{206} \mathrm{Bi}$. EXP [13] 
$\rightarrow$ for $\quad{ }^{208} \mathrm{~Pb}(\gamma, 6 \mathrm{n}){ }^{202} \mathrm{~Pb}, \quad{ }^{208} \mathrm{~Pb}(\gamma, 5 \mathrm{n}){ }^{203} \mathrm{~Pb} \quad$ and ${ }^{208} \mathrm{~Pb}(\gamma, 4 \mathrm{n}){ }^{204} \mathrm{~Pb}$ there is a several orders difference between LD3 model and the rest of the models, and experimental data is far from all of them;

$\rightarrow$ for $(\gamma, 3 n),(\gamma, 4 n),(\gamma, 5 n)$ and $(\gamma, 6 n)$ reactions on ${ }^{209} \mathrm{Bi}$ we observe that all theoretical models overestimate experimental data by several orders of magnitude;

\section{CONCLUSIONS}

In this work cross sections of photonuclear reactions, measured by different research groups were collected, systemized and compared with theoretical predictions. For some reactions theoretical values are in good agreement with experiment, for some of them we observe significant difference. Generally, at energies far from reaction thresholds, theoretical models which take into account pre-equilibrium mechanism describe experimental data better than those which operate with disabled pre-equilibrium mechanism. As a general conclusion from the analysis of the results obtained, we can assume that a shortage of experimental data significantly limits the possibilities of choice between different theoretical models and approaches. Overview provided in this work will facilitate search of the most reliable data, the work on estimation of available data and planning of new data obtaining.

\section{ACKNOWLEDGEMENTS}

Research was conducted in the scope of the IDEATE International Associated Laboratory (LIA).

\section{REFERENCES}

1. www.talys.eu

2. R. Capote et al. RIPL - Reference Input Parameter Library for calculation of nuclear reactions and nuclear data evaluation // Nucl. Data Sheets. 2009, v. 110 , p. 3107.

3. A. Gilbert, A.G.W. Cameron. A composite nuclearlevel density formula with shell corrections // Canadian J. of Phys. 1965, v. 43, p. 1446.

4. W. Dilg, W. Schantl, H. Vonach, M. Uhl. Level density parameters for the back-shifted Fermi gas model in the mass range $40<A<250 / /$ Nucl. Phys. A. 1973, v. 217 , p. 269.
5. A.V. Ignatyuk, K.K. Istekov, G.N. Smirenkin. Collective effects in level density, and the probability of fission // Soviet J. of Nucl. Phys. 1979, v. 29, № 4, p. 450.

6. A.V. Ignatyuk, J.L. Weil, S. Raman, S. Kahane. Density of discrete levels in ${ }^{116} \mathrm{Sn} / /$ Phys. Rev. C. 1993, v. 47, p. 1504.

7. V.G. Nedorezov, Yu.N. Ranyuk. Photofission of nuclei behind giant resonance. Kiev: "Naukova Dumka", 1989.

8. Schiff L.I. Energy-angle distribution of thin target bremsstrahlung // Phys. Rev. 1951, v. 83, p. 252.

9. B.S. Ishkhanov, I.M. Kapitonov. Interaction of electromagnetic radiation with atomic nuclei. Moscow: "Publishing house of the Moscow University", 1979.

10. Muhammad Zaman, Guinyun Kim, Haladhara Naik, Kwangsoo Kim, Sung-Gyun Shin, Mansoureh Tatari, Moo-Hyun Cho. Measurement of photo-neutron cross-sections of ${ }^{89} \mathrm{Y}$ with bremsstrahlung energies of 45 and $55 \mathrm{MeV} / /$ J. Radioanal. and Nucl. Chem. 2014, v. 299, p. 1739-1745.

11. Abul Kalam Md. Lutfor Rahman, Kunio Kato, Hidehiko Arima, Nobuhiro Shigyo, Kenji Ishibashi, Junichi Hori, Ken Naka Jima. Study on Effective Average $(\gamma, \mathrm{n})$ Cross Section for ${ }^{89} \mathrm{Y} ;{ }^{90} \mathrm{Zr} ;{ }^{93} \mathrm{Nb}$, and ${ }^{133} \mathrm{Cs}$ and $(\gamma, 3 \mathrm{n})$ Cross-Section for ${ }^{99} \mathrm{Tc} / / \mathrm{J}$. of Nucl. Sci. and Tech. 2010, v. 47, №7, p. 618-625.

12. Haladhara Naik, Guinyun Kim, Kwangsoo Kim, Muhammad Zaman, Ashok Goswami, Man Woo Lee, Sung-Chul Yang, Young-Ouk Lee, Sung-Gyun Shin, Moo-Hyun Cho. Measurement of flux-weighted average cross sections for ${ }^{197} \mathrm{Au}(\gamma, \mathrm{xn})$ reactions and isomeric yield ratios of ${ }^{196 \mathrm{~m} ; \mathrm{g}} \mathrm{Au}$ with bremsstrahlung // Nucl. Phys. A. 2016, v. 948, p. 28-45.

13. Haladhara Naik, Sarbjit Singh, Ashok Goswami, Vijay Kumar Manchanda, Guinyun Kim, Kyung Sook Kim, Man-Woo Lee, Md. Shakilur Rahman, Devesh Raj, Srinivasan Ganesan, SaraswatulaVenkata Suryanarayana, Moo-Hyun Cho, Won Namkung. Measurement of photo-neutron crosssections in ${ }^{208} \mathrm{~Pb}$ and ${ }^{209} \mathrm{Bi}$ with $50 \ldots 70 \mathrm{MeV}$ bremsstrahlung // Nucl. Instrum. and Methods. Phys. Res. $B, 2011$, v. 269, p. $1417-1424$.

Article received 16.10.2019

\section{СЕЧЕНИЯ В ФОТОЯДЕРНЫХ РЕАКЦИЯХ С МНОЖЕСТВЕННОЙ ЭМИССИЕЙ НЕЙТРОНОВ}

\section{О.А. Бесшейко, А.Н. Водин, Л.А. Голинка-Бесшейко, А.В. Котенко, В.А. Кушнир, А.В. Лубинец, В.В. Митроченко, С.Н. Олейник, С.A. Пережсогин, C. Vallerand}

Целью работы является изучение зависимости поперечных сечений в реакциях $A(\gamma, x \mathrm{n})(A-x \mathrm{n})$ от энергии гаммаквантов в диапазоне 19...70 МэВ, т. е. за пределами области большого дипольного резонанса. Экспериментальные данные были взяты из Международной базы данных EXFOR для широкого спектра ядерных масс $(55<A<209)$. Теоретические значения поперечных сечений получены с использованием кода TALYS-1.8. В наших симуляциях были рассмотрены несколько моделей плотности уровней с учетом предравновесных механизмов. Полученные результаты позволяют сделать выводы о различных механизмах фотоядерных реакций на некоторых ядрах и об их относительном вкладе в зависимости от энергии $\gamma$-квантов.

\section{ПЕРЕРІЗИ У ФОТОЯДЕРНИХ РЕАКЦІЯХ 3 МНОЖИННОЮ ЕМІСІЄЮ НЕЙТРОНІВ}

\section{О.А. Безшийко, О.М. Водін, Л.О. Голінка-Безшийко, А.В. Котенко, В.А. Кушнір, О.В. Лубинець, В.В. Мітроченко, С.М. Олійник, С.А. Пережогин, С. Vallerand}

Метою роботи $є$ вивчення залежності поперечних перерізів у реакції $A(\gamma, x \mathrm{n})(A-x \mathrm{n})$ від енергії гамма-квантів у діапазоні $19 . . .70 \mathrm{MeB}$, тобто за межами області великого дипольного резонансу. Експериментальні дані були взяті 3 міжнародної бази даних EXFOR для широкого спектра ядерних мас $(55<A<209)$. Теоретичні значення поперечних перерізів отримані з використанням коду TALYS-1.8. У наших симуляціях були розглянуті кілька моделей щільності рівнів 3 урахуванням передрівноважних механізмів. Отримані результати дозволяють зробити висновки про різні механізми фотоядерних реакцій на деяких ядрах і про їх відносний внесок у залежності від енергії $\gamma$-квантів. 